\title{
The Importance of Knowledge and Trust for Ethical Fashion Consumption
}

\begin{abstract}
Purpose- The clothing industry is one of the most polluting industries in the world, although manufacturers and retailers are trying to revert this tendency by applying ethical fashion principles. Drawing on the Knowledge-Attitude-Behavior (KAB) model or practice, this study aims to predict Chinese consumers' purchase intention of ethical fashion by employing and extending the Theory of Planned Behavior (TPB).

Design/methodology/approach- The extended TPB model incorporates knowledge of ethical fashion and trust in the fashion industry, two critical variables in ethical fashion literature, to explain the purchase intention of ethical fashion. Primary data from 245 Chinese respondents were collected in 2019. Model was tested and analyzed through structural equation modelling (SEM). Findings- Results show that the extended TPB model has higher predictability than the original TPB model. Attitude towards ethical fashion and subjective norm significantly predicts purchase intention while perceived behavioral control (PBC) does not. In addition, trust of ethical fashion is positively related to attitude towards ethical fashion and purchase intention, whereas knowledge of ethical fashion plays significant role in predicting trust and the three TPB factors. Subjective norm was found to have the most significant impact on consumers' intention to purchase ethical fashion, which shows that social pressure from one individual's reference group is the most dominant factor in forming consumer's purchase intention on ethical fashion.
\end{abstract}

Originality/value- The findings enrich the past literature on ethical fashion that trusting belief are salient determinants of consumers' attitude towards ethical fashion and purchase intention of ethical fashion products. The findings also supported the applicability of KAB and TPB in the domain of ethical consumption in the context of a developing country.

Keywords: ethical fashion, theory of planned behavior, SEM, knowledge, trust 


\section{INTRODUCTION}

The fashion industry currently is dominated by fast changing fashion. Such a dizzying speed of fashion consumption not only results in quickly moving production from factory to store, but also lead to tremendous amount of fashion waste (Morgan and Birtwistle, 2009). In addition, fast fashion brands tend to use cheap materials such as synthetic fibers which will end up in landfills and are unable to decay (Nïnimäki and Hassi, 2011). In fact, increasing consumers' conscience on fashion waste has brought about the rise of "ethical fashion" (Joergens, 2006). Currently consumer preference for ethical products has become the driving force for companies to employ ethical strategies in the marketplace (Kumar, 2017). Many leading fashion brands had started to promote sustainable supply chain management strategies to reduce the consumption of natural resources around the world. For example, H\&M has been selling its "Conscious Collection" since 2011, while Intimissimi has a long history of rebuying used products from their customers to reuse them and create new ones.

Consumers generally support sustainability; however, they need to have appropriate knowledge to make responsible purchases (Dickson, 2000). Knowledge about environmentally friendly issues would increase positive attitudes towards sustainable or ethical consumption, and have been theorised by many researches (Bly, et al., 2015). Knowledge is highlighted in consumer behavioural studies, which is perceived to consolidate the ground for trust (Han, Seo and Ko, 2017) thus alleviating uncertainty in economic interactions (Nuttavuthisit and Thøgersen, 2017; Hassan et al., 2013). Moreover, enterprises in the fashion industry have long been recognizing knowledge as a vital factor affecting their market value, and placing intensive efforts to incorporate it into their operation. Research even investigate which sources and types of knowledge are effective towards sustainable consumption in fashion industry (Kong et al., 2016). Under this circumstance, knowledge is widely detected in academic research about sustainable and ethical fashion, but rarely from the perspective of Knowledge-AttitudeBehavior (KAB). 
Research has revealed mixed findings regarding attitude and behavioral intention in ethical fashion consumption. Consumers who differed in subjective norms and perceived behavioral controls might result in various purchasing intentions, where knowledge offered an evaluation base, informatio nal source and affected personal beliefs whether the ethical product would bring up expected benefits (Ajzen et al., 2011; Liu et al., 2012; Paul et al., 2016). From attitudinal aspect, some studies have shown that consumers are often willing to buy ethical fashion products (Jin Gam, 2011) while other studies found consumers can be distrustful of ethical fashion brands (Joergens, 2006). The result indicates that, other than the cost and functional disadvantages, consumers may feel reluctant to purchase ethical apparel products due to informational shortage and lack of trust (Joergens, 2006). It is believed that consumer trust is the prerequisite for the establishment of ethical product, as many consumers fear being cheated when buying products with ethical claims ( $\mathrm{Du}, 2015)$. Therefore, present study used the TPB and $\mathrm{KAB}$ as the theoretical foundations and further attempts to include two additional constructs (i.e. Knowledge about Ethical Fashion and Trust in the Fashion Industry) in TPB as antecedents of ethical purchase intention.

The structure of the paper is organized as follows. A literature review with theoretical background and hypotheses is given in next section. After that, research methods and results with data analyses were introduced and reported. In the last section, conclusions with theoretical contribution and managerial implications are summarized.

\section{THEORETICAL BACKGROUND AND HYPOTHESIS DEVELOPMENT}

Within ethical consumption literature, tremendous studies have confirmed the efficacy of both theory of reasoned action (TRA) and the theory of planned behavior (TPB) in yielding insights into factors that impact individual behavioral intention. TPB extended and differed from TRA by including an 
exogenous variable perceived behavioral control (PBC). Since certain researchers claimed that PBC has better predication power and is more contextually grounded (Madden, Ellen and Ajzen, 1992), this research also adopts TPB as the major part of our model. Moreover, previous studies that have used the TPB model for ethical consumption have neglected the impact of ethical fashion knowledge and trust on consumer's purchase intention. Meanwhile, researchers that utilize KAB model rarely investigate the relationship between knowledge and the constructs in TPB. In addition, very few studies (Kim and Karpova, 2010; Becker-Leifhold, 2018) have employed TPB or KAB models to investigate the consumers' responses towards ethical fashion. To our best knowledge, none of the studies have measured the consumer's intention towards purchasing ethical fashion products in context of developing countries.

The study of ethical fashion consumption behavior in an emerging market like China is important because of two reasons. First, according to the World Trade Statistical Review (WTO, 2019), developing countries such as China, Bangladesh, and Viet Nam are the top producers and exporters of textile and clothing in the world. However, the adoption of ethical consumption in these countries are still in its infancy stage (Paul et al., 2016). Second, researchers have suggested that culture is important for ethical decision making (e.g. Cherry, 2006). Under the collectivist culture, consumers may follow different logic in relation to ethical fashion product consumption than that in western countries. For example, they tend to put more weight on social norms to create good feelings and a sense of belonging (Jung, Kim, and Oh, 2016). To fill the research gap, the study investigates the importance of knowledge and trust for ethical fashion consumption with following theoretical background and hypotheses.

\subsection{Ethical Fashion, Theory of Planned Behavior (TPB)}

Ethical fashion was defined as "fashionable clothes that incorporate fair trade principles with sweatshop-free labour conditions while not harming the environment or workers by using 
biodegradable and organic cotton" (Joergens, 2006). The relationship between people and the environment is one of the central concerns of ethical fashion (Lee, 2003; Lundblad and Davies, 2016). As consumers today not only demand for high-quality products, but also concern about corporate social responsibility and sustainability (Joy et al, 2012; Lundblad and Davies, 2016), their preference for ethical products has become the driving force for companies to employ ethical strategies in the marketplace (Kumar, 2017; Mo et al, 2018). Recently, sustainability and ethical conduct start to matter in fashion industry. Increasingly, people begin to realize that the success of the change in consumption patterns depends not only on the supply of products in the market, but also on consumers' choice, behavior, and way of life (Wang et al., 2014).

The theory of planned behaviour (TPB; Ajzen, 1991) is one of the most influential models employed by several studies regarding sustainable consumption, such as green purchase behaviors (Yadav and Pathak, 2016; Paul, Modi, and Patel, 2016), visiting environmental restaurant and hotels (Chen and Tung, 2014), adopting hybrid electric vehicles (Wang et al., 2016), and consumption of organic food (Nuttavuthisit and Thøgersen, 2017). Table 1 summarizes some of the recent studies employing and extending the TPB model in context of ethical consumption.

\section{Table 1 here}

The TPB suggests that attitudes, subjective norm, and perceived behavioral control (PBC) are three principal factors that determine behavioral intention, which leads to actual behavior (Ajzen, 2002). Ajzen (1991) defined a persons' attitude toward a specific behavior as how favorably an individual evaluates the behavior in question. If a person believes that a certain behavior will result to a positive outcome, he or she may hold a favorable attitude toward the behavior and vice versa (Chen and Tung, 2014). In the context of ethical fashion, a positive relationship between attitude and behavioral intention has been established across many cultures (Zhou et al., 2015; Lundblad and Davies, 2016). The 
subjective norm is defined as "perceived social pressure to perform or not perform a behavior" (Ajzen, 1991). It refers to the perceived social pressure from important reference group (e.g. family members, close friends, and colleagues) to a particular behavior, and whether or not an individual will consider the pressure when deciding to act the behavior. In the context of fashion, the pressure toward ethical conducts of fashion brands are dominant (Lundblad and Davies, 2016); the pressure would not only affect companies to address the societal impacts of their operations, but also affect consumers to be in line with the sustainable behavior. When consumers perceive that significant others endorse ethical fashion, they are more prone to adopt these behaviors (Jin Gam, 2011). Finally, perceived behavioral control is an individual's perception about whether performing a certain behaviour is easy or difficult (Ajzen, 1991). Perceived behavioral control depends on past experience and anticipated obstacles. Many studies have shown that PBC is positively related to intention in various sustainable activities, such as visiting green hotels (Chen and Tung, 2014) and organic food consumption (Nuttavuthisit and Thøgersen, 2017). Based on previous research, we proposed the following hypotheses:

H1a: The attitude towards ethical fashion has positive impacts on the intention to purchase ethical fashion.

H1b: Subjective norms regarding buying ethical fashion have positive impacts on the intention to purchase ethical fashion.

H1c: The PBC of buying ethical fashion has positive impacts on the intention to purchase ethical fashion.

\subsection{Trust in the Fashion Industry and TPB}

According to Bonini and Oppenheim $(2008, \mathrm{p} 56)$, there are five barriers for sustainable consumption, namely lack of awareness, negative perceptions, distrust, high prices, and low availability. Previous studies have indicated that trust is a crucial antecedent for most economic interactions when uncertainty 
exists (e.g. Nuttavuthisit and Thøgersen, 2017; Hassan et al., 2013). Attributes of ethical fashion products are credence attributes, which means that they cannot be verified by the consumer even after purchase and consumption (Balineau and Dufeu, 2010). Hence, many consumers fear being cheated when buying products with ethical claims (Hassan et al., 2013). This is especially the case since the ethical fashion products are generally priced higher than ordinary products due to the high cost of labor, material and certification (Niinimäki and Hassi, 2011). Currently, there is a lack of research on how trust influences consumer decision-making and behavior in the domain of ethical fashion.

Since most consumers do not have the technical expertise and other resources to verify the ethical claims, trust in the ethical fashion is essential for consumers to buy it (Lundblad and Davies, 2016). In many cases, only after consumers gained more practical knowledge about ethical or eco-fashion products, they express a willingness and intention to learn more about fashion and even to engage in future fashion product buying (Han, Seo and Ko, 2017); before having knowledge or expertise about ethical claims, trust can play an important role to enhance consumers' behavioral intentions (Bonn, Cronin \& Cho, 2016). In other words, they need to believe that it can contribute to solve environmental problems through their own efforts and their everyday purchase behavior (Straughan and Roberts, 1999). In a word, trust in the fashion industry increases consumers' positive attitudes toward ethical products and forms intention to purchase ethical fashion. The following hypothesis is therefore proposed:

H2a: Trust in the fashion industry has positive impacts on attitude towards ethical fashion.

H2b: Trust in the fashion industry has positive impacts on the intention to purchase ethical fashion.

\subsection{KAB, trust, and TPB}

The $\mathrm{KAB}$ model has been proposed as a way of explaining the role of knowledge, in which the 
behavior changes gradually and has been utilized in academic research in information security, health, environment, education, clinical service areas (Yi and Hohashi, 2018; McCormac et al., 2017), rarely in ethical domain, resulting in behavioral change after a period of time. Researchers have shown that increase in knowledge can lead to change in behavior, however, it is not the only factor (Kim and Loewenstein, 2020). The present research introduce trust as another factor and integrate it into $\mathrm{KAB}$ and TPB theories.

Studies have shown that although consumers generally support ethical business practices, they are often not equipped with appropriate knowledge to make purchase decisions of ethical products (Dickson, 2000). Consumers also seem to lack trust in the motivations for fashion brands' ethical conduct, if not for mere commercial incentives (Cervellon and Wernerfelt, 2012). Fearing the accusations of greenwashing, many companies hesitate to publicize their green policies (Hopkins, 2009), which also discourage the fashion industry to diffusing knowledge on their sustainable practices. It is consistent with the finding of Ajzen et al. (2011), knowledge is a crucial prerequisite for effective action. Consumers often experience knowledge, evaluation and choice uncertainties in decision-making processes, especially in relation to products such as ethical fashion (Hassan et al., 2013). Knowledge and trust have been found to be highly and positively correlated in green product field. For example, limited or incorrect knowledge of the production standards underpinning a specific labelling scheme might lead consumers' distrusting of the labelled products (Nuttavuthisit and Thøgersen, 2017). For consumers to have better access and knowledge concerning the business practice claims of many companies, transparency in the supply chain is increasingly required, especially for apparel firms (Perry and Towers, 2009).

Beliefs are based on knowledge, or that which the individual perceives to be true. In the original TPB model, beliefs constitute the informational foundation that ultimately determines behavior (Ajzen et al., 2011). Specifically, beliefs about the likely consequences of a specific behavior are assumed to 
determine the attitudes toward that specific behavior. In the context of fashion, it makes sense that heightened knowledge about ethical fashion would lead to stronger beliefs about the positive consequences or benefits of the ethical and sustainable conducts. In addition, beliefs about the expectations and behaviors of others (normative beliefs) are assumed to determine subjective norms (Ajzen, 2002). Mun et al. (2014) conducted an online survey of 276 female undergraduates and found that the key to retail borrowing intention is knowledge about other people's positive attitudes and positive experiences with retail borrowing. Paul et al., (2016) surveyed 521 highly educated respondents in India and found that individuals with more knowledge of green products may also influence others' behavior via peer group/family pressure. Lastly, perceived behavioral control (PBC) is assumed to be determined by beliefs about potential facilitating or inhibiting factors (Ajzen, 2002). Knowledge of ethical fashion clearly enhances the control belief of ethical fashion consumption, as it enhances the perception of information availability (Ajzen et al., 2011) and reduces uncertainty in ethical choices (Hassan et al, 2013). Therefore, the present study added knowledge of ethical fashion as an antecedent of trust in the fashion industry, attitude, subjective norm, and $\mathrm{PBC}$ to the $\mathrm{KAB}$ and TPB models. Specifically, the following hypothesis were proposed:

H3a: The knowledge about ethical fashion has positive impacts on the trust in the fashion industry.

H3b: The knowledge about ethical fashion has positive impacts on the attitude towards ethical fashion.

H3c: The knowledge about ethical fashion has positive impacts on the subjective norm.

H3d: The knowledge about ethical fashion has positive impacts on the PBC.

In summary, the current study adopts the TPB as theoretical framework to explain customers' intentions to purchase ethical fashion. The TPB model is integrated with domain specific factors (i.e. knowledge 
and trust), which is depicted in Figure 1.

Figure 1 here

\section{METHODOLOGY}

\subsection{Questionnaire design and Measurements}

A questionnaire was designed with all measurements adopted from relevant previous studies. Since the target samples are consumers from mainland China, the measurement items were first translated into Chinese from the original English version. To be more suitable to the Chinese context, some wording was modified but the content validity of the measurement was not affected. The survey instrument was then back translated to English to ensure equivalence between the items in both languages (Buil, de Chernatony, and Martínez, 2008).

Seven-point Likert-type and semantic differential scales were used to measure all the constructs in the conceptual model, where 1 represented the participant's total disagreement with the proposed statement and 7 meant total agreement with it. Knowledge about Ethical Fashion was measured with the threeitem scale originally proposed by Söderlund (2002). Trust in the Fashion Industry was measured with the four-item scale taken from Morgan and Hunt (1994). The four scales related to the TPB were all taken from Kim and Karpova (2010). Attitude towards Ethical Fashion was evaluated with a five-item

scale, whereas Subjective Norm, Perceived Behavioral Control and Intention to Purchase Ethical Fashion were measured with three-item scales. Table 3 presents all the items.

\subsection{Participants and Data Collection}


The target group of this study was potential consumers of fashion apparel goods in mainland China. An online survey was conducted for collecting data. The questionnaire was placed on the Sojump website (https:/www.wjx.com), which is one of the leading online survey platforms in China. It has over three million active sample resources all over China with diverse demographic backgrounds. Each valid participant of this study was rewarded with 20 RMB (about 3 USD) for their effort. The reward-based approach could help increase the response rate and reduce the occurrence of invalid samples. A few recent studies have used Sojump as the platform to recruit samples for their research in China (e.g. Lien et al. 2017; Liu and Liu, 2019; Liu and Liu, 2020). As general consumers may not be informed about fashion brands' ethical practices, each respondent was asked to read the provided information about ethical fashion before answering the questionnaire (See Appendix). The procedure of offering materials to respondents to stimulate their awareness has also been documented in previous studies (Sen, Bhattacharya, and Korschun, 2006; Tseng, Balabanis, and Liu, 2018; Liu et al., 2020). However, it may also cause common method bias which would lead respondents to rate sustainability initiatives higher. Statistical analyses were performed to assess the severity of common method bias. First, following Podsakoff et al. (2003) and Liang et al. (2007), a method factor test was employed by using by using SmartPLS. Specifically, the proposed model was added with a common method factor whose indicators included all the principal factors' indicators and calculated each indicator's variances substantively explained by the principal factors and by the method. Second, the full collinearity assessment approach was employed to test common method bias by using SmartPLS3 (Kock, 2015). The assessment included four steps. First, add a new column to the original dataset with random values (preferably varying from 0 to 1 ) as the dummy variable. Second, create a model where all of the latent variables point at the new random dummy variable. Third, run a SEM analysis using the PLS algorithm. Forth, inspect the table with the variance inflation factors (VIFs). The model could be considered free of common method bias if all VIFs are equal to or lower than 3.3 (Kock, 2015). 
The online survey link was open from July 2019 to August 2019 and had 250 respondents voluntarily completed the questionnaire, while 60 respondents did not complete the questionnaire. After removing 5 invalid questionnaires from respondents who provided same rating across the entire questionnaire, 245 responses were considered valid and usable. To check the potential of non-response bias, an independent sample t-test was conducted on respondents who completed the questionnaire and those who did not (Irfan, Wang, and Akhtar, 2019). The results indicated that there was no issue of non-response bias since no significant difference was found between the two groups such as age $(p=.54)$, gender $(p$ $=.19)$, education $(p=.11)$, relationship with fashion industry $(p=.10)$, frequency of purchasing fashion products $(p=.21)$, and spending on their last fashion-shopping trip $(p=.90)$.

\section{RESULTS}

\subsection{Sample characteristics}

The majority of the sample (69.39\%) was female. The mean age of the respondents was 35.80 years old with a range from 18 to 69. In terms of education, most of the respondents (about $61.22 \%$ ) had an undergraduate degree or higher. As for the relationship with fashion industry, $80.00 \%$ of the respondents were customers, while the remaining $20.00 \%$ of them were employed by fashion manufactures, brands, and others. Regarding the frequency of purchasing fashion products, $54.70 \%$ of the respondents occasionally made a purchase, while $45.30 \%$ of them bought fashion products several times a month. With regards to spending on their last fashion-shopping trip, $6.53 \%$ of the respondents spend less than 15 euro, $24.90 \%$ spend between 15 to 30 euros, $33.9 \%$ spend between 30 to 60 euros, and $34.69 \%$ spend more than 60 euros in their last fashion-shopping trip. Table 2 illustrates the demographic characteristics of the sample. 
Table 2 here

\subsection{Measurement model: reliability and validity}

To assess the measurement constructs, exploratory factor analysis (EFA) was conducted by using IBM SPSS Statistics 24. The EFA results (see Table 3) showed that the factor loadings of the six factors were all above 0.50 and there was no cross-construct loading. Cronbach's alpha coefficient $(\alpha)$ for each of the constructs ranged from 0.71 to 0.89 , indicating good reliability of the measures.

Confirmatory factor analysis (CFA) was conducted by using IBM SPSS AMOS 24 to further assess the validity of measurements. The results showed that the six-factor measurement model had good fit $\left(\chi^{2}\right.$ $=263.67, d f=155, \chi^{2} / d f=1.70, C F I=0.96, I F I=0.96$, and $\left.R M S E A=0.05\right)$. The goodness of fit statistics illustrated that the model fits well to the data (Bentler, 1990). All the average variance extracted (AVE) for each construct was above 0.50 . Such result supports the convergent validity of the measures (Hair et al, 2013). Discriminant validity was confirmed as the square root of the AVE (diagonal elements in Table 4) was larger than the corresponding correlation coefficient between factors (Fornell and Larcker, 1981).

Table 5 illustrated the results of common method bias analysis by using method factor test recommended by Liang et al. (2007). The results demonstrate that the average substantively variance of the measurement items is 0.72 , while the average method-based variance is 0.01 . The ratio of substantive variance to method variance is about $72: 1$. Given the small magnitude and insignificance of method variance, it can be concluded that the common method bias is acceptable for the following data analysis. In addition, the full collinearity assessment approach was also employed to test common method bias. As shown in Table 5, the VIFs obtained for all the latent variables in the proposed model were lower than the cut-off value 3.3. Therefore, the model can be considered free of common method 
bias (Kock, 2015).

Table 3 here

Table 4 here

Table 5 here

\subsection{Structural model: model comparisons and hypotheses testing}

Structural equation modelling was conducted by using IBM SPSS AMOS 24 to test the proposed hypotheses. The original TPB model (excluding the knowledge and trust) was compared with the extended version of the TPB model. The extended model exhibited good model fit $\left(\chi^{2}=321.10, d f=\right.$ $\left.161, \chi^{2} / d f=1.99, C F I=0.94, I F I=0.94, R M S E A=0.06\right)$ and is better than the original TPB model $\left(\chi^{2}\right.$

$\left.=164.01, d f=61, \chi^{2} d f=2.69, C F I=0.93, I F I=0.93, R M S E A=0.08\right) . \quad$ In addition, including knowledge about ethical fashion and trust in the fashion industry in TPB resulted in higher explanatory power for purchase intention $\left(\mathrm{R}^{2}=0.56\right)$ than in the original TPB model $\left(\mathrm{R}^{2}=0.48\right)$. The findings therefore supported the inclusion of knowledge and trust in the TPB model regarding intention to purchase ethical fashion.

Table 6 shows the results regarding the proposed hypotheses. In the original TPB model, Attitude towards ethical fashion $(\beta=0.32, p<0.001)$ and subjective norm $(\beta=0.62, p<0.001)$ were significantly related to consumers' intention to purchase ethical fashion. In the extended TPB model, Attitude towards ethical fashion $(\beta=0.24, p<0.001)$ and subjective norm $(\beta=0.49, p<0.001)$ were also significantly related to consumers' intention to purchase ethical fashion. The results therefore supported H1a and H1b. However, the regression weight from $\mathrm{PBC}$ to intention to purchase ethical 
fashion is not significant in both original TPB model and extended TPB model. H1c was therefore not supported. Trust in the fashion industry had a significant positive influence on the attitude towards ethical fashion $(\beta=0.21, p<0.05)$ and intention to purchase ethical fashion $(\beta=0.24, p<0.01)$, which supported the $\mathrm{H} 2 \mathrm{a}$ and $\mathrm{H} 2 \mathrm{~b}$. Further, significant positive influences of knowledge of ethical fashion were found on trust in the fashion industry $(\beta=0.60, p<0.001)$, attitude towards ethical fashion $(\beta=$ $0.25, p<0.001)$, subjective norm $(\beta=0.70, p<0.001)$, and $\operatorname{PBC}(\beta=0.70, p<0.001)$. The results therefore supported $\mathrm{H} 3 \mathrm{a}, \mathrm{H} 3 \mathrm{~b}, \mathrm{H} 3 \mathrm{c}$, and $\mathrm{H} 3 \mathrm{~d}$. In addition, a bootstrap analysis with 1,000 replications was performed by using AMOS 24 to test the mediation. As shown in Table 6, knowledge of ethical fashion had a significant indirect effect on purchase intention (95\% confidence interval (CI) [0.48, $0.66])$ and a significant indirect effect on attitude $(95 \% \mathrm{CI}[0.04,0.24])$. The results also confirmed the significant indirect effect on the relationship between trust in the fashion industry and purchase intention via attitude $(95 \% \mathrm{CI}[0.01,0.13])$.

Table 6 here

\section{CONCLUSIONS}

The results suggested that Chinese consumers' intention to buy ethical fashion can be predicted by attitude, subjective norm, trust in the fashion industry, as well as knowledge of ethical fashion. The inclusion of two domain specific factors (i.e. trust in the fashion industry and knowledge of ethical fashion) in the TPB model were supported since the extended TPB model has significantly higher predictive power $(56 \%)$ than the original TPB model has $(48 \%)$. Results also indicated that the perceived knowledge of ethical fashion among the Chinese consumer is lower (mean rating of knowledge is $4.38 / 7$; see table 4) than the purchase intention of ethical fashion (5.82/7), which illustrated the importance of diffusing knowledge and creating awareness related to the ethical fashion 
in developing nations.

Unlike previous studies in which subjective norm had been identified as the weakest link in intention models (Ajzen, 1991; Paul et al., 2016), subjective norm was found to have the most significant impact on consumers' intention to purchase ethical fashion, which shows that social pressure from one individual's reference group is the most dominant factor in forming consumer's purchase intention on ethical fashion. Such result is reasonable since Asians tend to value collectivism (Sivadas, Bruvold, and Nelson, 2008). In the context of China, consumers were likely to have collectivism values, which means that the beliefs and behaviours of their significant others (e.g. family members, friends, and colleagues) would influence their purchasing decisions. Attitude towards ethical fashion also had a significant influence on the consumer intention to buy ethical fashion, which supported the findings of earlier studies (Lundblad and Davies, 2016; Becker-Leifhold, 2018). Furthermore, PBC was found to be a non-significant predictor of purchase intention in both original TPB model and extended TPB model. Such finding is not too surprising given the mixed results from previous studies regarding the relationship between PBC and intention. For example, Venkatesh et al. (2003) found that PBC was only significantly related to intention in some of the relationships, and Riemenschneider et al. (2003) reported a non-significant result when testing the relationship between PBC and intention in any of their hypothesized models. The research has inspired the application of TPB in sustainable consumption literature. Overall, Fishbein and Ajzen (1975) have prominently contribute to consumer research in the field of attitude and decision-making by establishing the Theory of Reasoned Action (TRA) and the Theory of Planned Behavior (TPB). TPB is an expectancy value model extended from TRA, which include perceived behavioral control (PBC) that explains personal volitional controls over their behaviors (Ajzen, 1991). However, considering that PBC has non-significant influence on purchase intention in our study, which echoes with TRA model with two major antecedents of behavioral intention, the study reveals that TRA model could be more appropriate than TPB in explaining ethical 
fashion consumption in similar research context and setting.

\subsection{Theoretical contribution}

This paper has two major theoretical contributions for new advances in attitude and decision-making literature, encompassing: the evolvement of the TRA/TPB model by including additional constructs (Trust and Knowledge) not within the original conceptualization of the theory and the model extension by combing with Knowledge-Attitude-Behavior (KAB) model.

Trust in the fashion industry was found to be a significant predictor of attitude towards ethical fashion and purchase intention of ethical fashion products. Such findings enrich the past literature on ethical fashion that trusting belief are salient determinants of consumers' attitude towards ethical fashion and purchase intention of ethical fashion products. This study confirmed that trusting belief could enable more favorable expectations of outcomes from ethical conducts and thereby a more positive attitude (e.g., Nuttavuthisit and Thøgersen, 2017). This was done by analyzing the impact of trust within the TPB model (i.e. controlling for influences of attitude, subjective norm, and PBC), which is one of the most comprehensive and widely used theoretical framework in consumer behavior research (Ajzen, 2011). As discussed above, the TPB model has previously been employed in several studies of ethical fashion (e.g. Kim and Karpova, 2010; Becker-Leifhold, 2018). However, rarely have these studies included the importance of trust for consumer decision-making and behavior.

Notably, knowledge of ethical fashion was found to have significant impacts on trust in the fashion industry, attitude towards ethical fashion, subjective norm, and PBC. Such finding echoed the findings of Paul et al. (2016), Yadav and Pathak (2016) that knowledge and concern plays a critical role in proenvironmental behavior such as ethical fashion, which is also an extend of KAB utilization. Overall, the findings supported the applicability of KAB and TPB in the domain of ethical consumption in the context of China, a developing country. 
Unlike results from other research (e.g. Yadav and Pathak, 2016; Paul et al., 2016), of the three variables in the original TPB model, subjective norm was found to be strongest predictor of intention to purchase ethical fashion products instead of attitude towards ethical fashion. The result suggested that consumers in China may be more influenced by their perceived social pressure than their own attitude. Such result also revealed that cultural differences among the countries could be a possible explanation for the non-significant impact of PBC on the intention to purchase ethical fashion products.

\subsection{Managerial implications}

Knowledge of ethical fashion plays an important role in customers' trust and attitudes towards ethical fashion. Therefore, fashion brand managers should not hesitate to openly reveal their ethical policies and initiatives; instead, they need to design marketing communications and advertising to educate their customers about ethical fashion. The findings also revealed that customers' trust in the fashion industry would lead to positive attitude and purchase intention of ethical fashion product. Fashion brands therefore should display their supply chain more transparently through information about outsourcing, sweatshop-free labor conditions, pollution prevention, green materials, fair trade, and so on.

As knowledge of ethical fashion has been found to be significant in predicting trust and the other three TPB factors, such findings thus offer implications on the creation and marketing of relevant knowledge and related products. Presently, many universities and business association have conducted research and development for the use of ethical materials for clothing. The extraction for natural coloring agent as natural dyeing materials is one of the examples and has been generally considered as an environmentally friendly way to substitute the use of chemical dye by scientists and merchants (Adeel et al., 2017). How to transfer, reinforce and market this kind of growing knowledge to customers appears to be quite crucial.

Besides firms' own effort in marketing, it is popular in the western countries that the clothing businesses 
unified their green marketing effort and initiative via industry councils and coalitions (e.g. Green Textile Associates, 2020; Ethical Clothing Australia, 2020; Ethical Fashion Initiative, 2020). Whereas further online searching shows that the strategies to use unified actions by local clothing businesses to support marketing of ethical fashion and associated knowledge have been in paucity in developing nations at the moment.

To communicate the ethical actions being implemented to outsiders and stakeholders, many fashion and clothing corporations have initiated the CSR reporting including the use of ISO 26000 standards and its ethical areas to communicate their measures undertaken (Colucci, Tuan, and Visentin, 2020). Such a practice has no doubt to reinforce consumers' confidence and knowledge about ethical fashion. Moreover, youngsters have become IT savvy; electronic marketing using various types of social media have been seen to be more appealing than other means. Thus, reserving space in online mall for briefing ethical clothing knowledge and product could be an appropriate marketing channel, especially given the voluminous online trading transaction status in China.

\subsection{Limitations and future research}

The first limitation of this study is that it was carried out only in one country, which means that participating consumers' response might be influenced by the specific national culture. For example, one possible explanation for the non-significant relationship between $\mathrm{PBC}$ and the intention to purchase ethical fashion in China may be due to the cultural differences among the countries in which previous studies have taken place. This research investigates consumer decision-making in an ethical fashion consumption context, where consumer uncertainties are common (Hassan et al, 2013). The uncertainty avoidance dimension may be particularly important in ethical fashion area as represented in this study. The aversion against losing face is particularly strong in Asian cultures (Komin, 1990), which may lead consumers to be more sensitive to risks of being cheated. Consumers in Western 
cultures exhibit a low uncertainty avoidance index, which means that they are more prone to risk taking and to assume changes (Merkin, 2006). Thus, while consumers in low uncertainty avoidance cultures may be comfortable to make purchase decision of ethical fashion with incomplete information, consumers in high uncertainty avoidance cultures may feel overwhelmed with the uncertainty of not getting the necessary information. This may explain why $\mathrm{PBC}$ was not found to be a significant predictor of the intention to purchase ethical fashion products. Thus, the findings of the current study need to be replicated in different cultural contexts.

The second limitation lie with the procedure of offering materials to respondents before the survey. For the cross-sectional study like this, any elements of design that can create bias especially at the beginning of the questionnaire will corrupt the value of the research. The respondents' authentic knowledge and attitude will be affected by arbitrary promotion of the ethical aspects of fashion industry (either positive or negative). The current study is likely to show only the impact of the positive ethical aspect of the industry or the firm on consumer attitude or intention. Future studies, therefore, are encouraged to use experiments to test the proposed model to enhance the internal validity of the findings.

The third limitation of this study is related to the data collection process. As a common limitation in ethical customer decision-making research, the data is generated from stated intentions or self-reported behaviors, rather than observed actual behaviors. Participants may present social desirability bias in their answers. Additionally, the survey platform only distributed the survey link to potential respondents for their participation. Respondents can decide whether or not open the link based on the topic. The self-selection biases of the respondents are therefore inevitable, which may bias the research findings since only those who are more interested in the topic would have motivated to respond.

Fourth, the study has used only measured the subjective knowledge to analyze the influence of 
knowledge about ethical fashion. However, as suggested by Barber, Taylor, and Strick (2009), both subjective and objective knowledge should be measured for their impacts. Therefore, future studies could measure both subjective and objective knowledge of ethical fashion and test their predictive power in the extended TPB model.

Lastly, despite the extensive research utilizing TPB to understand different ethical consumption factors

or contexts, there has been limited research on the focal outcome, the behavior. Our study only measures respondents' intention not their actual behavior. Future studies are thus needed to include the actual behavior regarding ethical fashion consumption, which will help to enhance the external validity of the research findings and link the relationship between purchase intention and actual purchasing behavior.

\section{REFERENCES}

Adeel, S., Gulzar, T., Azeem, M., Saeed, M., Hanif, I., and Iqbal, N. (2017), “Appraisal of marigo ld flower based lutein as natural colourant for textile dyeing under the influence of gamma radiations", Radiation Physics and Chemistry, Vol. 130, pp. 35-39.

Ajzen, I. (1991), "The theory of planned behavior", Organizational Behavior and Human Decision Processes, Vol. 50, pp. 179-211.

Ajzen, I. (2002), 'Perceived behavioral control, self-efficacy, locus of control, and the theory of planned behavior", Journal of Applied Social Psychology, Vol. 80 No. 6, pp. 2918-2940.

Ajzen, I., Joyce, N., Sheikh, S., and Cote, N. G. (2011), 'Knowledge and the prediction of behavior: The role of information accuracy in the theory of planned behavior", Basic and Applied Social Psychology, Vol. 33 No. 2, pp. 101-117.

Balineau, G., and Dufeu, I. (2010), “Are Fair Trade goods credence goods? A new proposal, with French illustrations", Journal of Business Ethics, Vol. 92 No. 2, 331-345. 
Barber, N., Taylor, C., and Strick, S. (2009), 'Wine consumers' environmental knowledge and attitudes: Influence on willingness to purchase", International Journal of Wine Research, Vol. 1 No. 1, pp. 59-72.

Bly, S. , Gwozdz, W. , and Reisch, L. A. (2015), 'Exit from the high street: an exploratory study of sustainable fashion consumption pioneers", International Journal of Consumer Studies, Vol. 39 No. 2, pp. 125-135.

Becker-Leifhold, C. V. (2018), "The role of values in collaborative fashion consumption- A critical investigation through the lenses of the theory of planned behavior", Journal of Cleaner Production, Vol. 199, pp. 781-791.

Bentler, P. M. (1990), 'Fit indexes, lagrange multiples, constraint changes, and incomplete data in structural models", Multivariate Behavioral Research, Vol. 25, pp. 163-172.

Bonini, S., and Oppenheim, J. (2008), "Cultivating the green consumer”, Stanford Social Innovation Review, Vol. 6 No. 4, pp. 56-61.

Bonn, M. A., Cronin, J. J, and Cho, M. (2016), 'Do environmental sustainable practices of organic wine suppliers affect consumers' behavioral intentions? The moderating role of trust", Cornell Hospitality Quarterly, Vol. 57 No. 1, pp. 21-37.

Buil, I., de Chernatony, L. and Martínez, E. (2008), "A cross-national validation of the consumerbased brand equity scale", Journal of Product and Brand Management, Vol. 17 No. 6, pp. 384-392.

Cervellon, M. C., and Wernerfelt, A. S. (2012), 'Knowledge sharing among green fashion communities online: Lessons for the sustainable supply chain”, Journal of Fashion Marketing and Management: An International Journal, Vol. 16 No. 2, pp. 176-192.

Chen, M. F., and Tung, P. J. (2014), 'Developing an extended theory of planned behavior model to predict consumers' intention to visit green hotels", International Journal of Hospitality 
Management, Vol. 36, pp. 221-230.

Cherry, J. (2006), "The impact of normative influence and locus of control on ethical judgments and intentions: A cross-cultural comparison", Journal of Business Ethics, Vol. 68 No. 2, pp.113132.

Colucci, M., Tuan, A., and Visentin, M. (2019), "An empirical investigation of the drivers of CSR talk and walk in the fashion industry", Journal of Cleaner Production, Vol. 248, pp. 1-8.

Dickson, M. A. (2000), 'Personal values, beliefs, knowledge, and attitudes relating to intentions to purchase apparel from socially responsible businesses", Clothing and Textiles Research Journal, Vol. 18 No. 1, pp. 19-30.

Du, X. (2015), "How the market values greenwashing? Evidence from China", Journal of Business Ethics, Vol. 128 No. 3, pp. 547-574.

Ethical Clothing Australia (2020). Home page. Retrieved January 17, 2020 from https:/ethicalclothingaustralia.org.au/

Ethical Fashion Initiative (2020). Ethics. Retrieved January 17, 2020 from https:/ethicalfashioninitiative.org/ethic

Fishbein, M., \& Ajzen, I. (1975), Belief, attitude, intention, and behavior: An introduction to theory and research. Reading, MA: Addison Wesley.

Fornell, C., and Larcker, D. F. (1981), "Evaluating structural equation models with unobservable variables and measurement error", Journal of Marketing Research, Vol. 18 No. 1, pp. 39-50.

Green Textile Associates (2020). Green Textile Associates, Inc. Retrieved January 17, 2020 from https:/www.globalspec.com/supplier/profile/GreenTextileAssociates

Han, J., Seo, Y., and Ko, E. (2017), "Staging luxury experiences for understanding sustainable fashion consumption: A balance theory application”, Journal of Business Research, Vol. 74, pp. 162167. 
Hair, J. F., Black, W. C., Babin, B. J., and Anderson, R. E. (2013), Multivariate data analysis: Pearson new international edition, 7th ed., Pearson, Harlow.

Hassan, L., Shaw, D., Shiu, E., Walsh, G., and Parry, S. (2013), "Uncertainty in ethical consumer choice: a conceptual model", Journal of Consumer Behaviour, Vol. 12 No. 3, pp. 182-193.

Hopkins, M. S., and Roche, C. (2009), 'What the 'Green' consumer wants”, MIT Sloan Management Review, Vol. 50 No. 4, p. 87.

Irfan, M., Wang, M. and Akhtar, N. (2019), "Enabling supply chain agility through process integration and supply flexibility: Evidence from the fashion industry", Asia Pacific Journal of Marketing and Logistics, Vol. 32 No. 2, pp. 519-547.

Jin Gam, H. (2011), "Are fashion-conscious consumers more likely to adopt eco-friendly clothing?" Journal of Fashion Marketing and Management: An International Journal, Vol. 15 No. 2, pp. 178-193.

Joergens, C. (2006), "Ethical fashion: Myth or future trend?” Journal of Fashion Marketing and Management: An International Journal, Vol. 10 No. 3, pp. 360-371.

Joy, A., Sherry Jr, J. F., Venkatesh, A., Wang, J., and Chan, R. (2012), 'Fast fashion, sustainability, and the ethical appeal of luxury brands", Fashion Theory, Vol. 16 No. 3, pp. 273-295.

Jung, H. J., Kim, H., and Oh, K. W. (2016), "Green leather for ethical consumers in China and Korea: Facilitating ethical consumption with value-belief-attitude logic", Journal of Business Ethics, Vol. 135 No. 3, pp. 483-502.

Kemm, J. R., and Close, A. (1995), Health promotion: theory and practice. Macmillan International Higher Education.

Kim, H., \& Karpova, E. (2010), "Consumer attitudes toward fashion counterfeits: Application of the theory of planned behavior", Clothing and Textiles Research Journal, Vol. 28, No. 2, pp. 7994. 
Kim, J., \& Loewenstein, J. (2020), "Analogical encoding fosters ethical decision making because improved knowledge of ethical principles increases moral awareness", Journal of Business Ethics, https//doi.org/10.1007/s10551-020-04457-w

Kock, N. (2015), "Common method bias in PLS-SEM: A full collinearity assessment approach", International Journal of e-Collaboration, Vol. 11 No. 4, pp. 1-10.

Komin, S. (1990), Psychology of the Thai people: Values and behavioral patterns. Research Center, National Institute of Development Administration.

Kong, H. M., Ko, E., Chae, H., and Mattila, P. (2016), 'Understanding fashion consumers' attitude and behavioral intention toward sustainable fashion products: Focus on sustainable knowledge sources and knowledge types", Journal of Global Fashion Marketing, Vol. 7 No. 2, pp. 103-119.

Kumar, P. (2017), "Intents of green advertisements", Asia Pacific Journal of Marketing and Logistics, Vol. 29 No. 1, pp. 70-79.

Lee, M. (2003), Fashion victim: Our love-hate relationship with dressing, shopping, and the cost of style. New York: Broadway Books.

Liang, H., Saraf, N., Hu, Q., and Xue, Y. (2007), "Assimilation of enterprise systems: the effect of institutional pressures and the mediating role of top management", MIS Quarterly, Vol. 31 No. 1, pp. 59-87.

Lien, C. H., Cao, Y., and Zhou, X. (2017), "Service quality, satisfaction, stickiness, and usage intentions: An exploratory evaluation in the context of WeChat services", Computers in Human Behavior, Vol. 68, pp. 403-410.

Liu, M. T., Brock, J., Singh, R., Chu, R., Sy-Changco, J. (2012), "What drives Indian consumer credit card loyalty? The perspective of involvement in reward programmes", The International Review of Retail, Distribution and Consumer Research, Vol. 22 No. 4, pp. 365-383. 
Liu, M. T., Liu, Y., and Mo,Z. (2020), "Moral norm is the key: An extension of the theory of planned behaviour (TPB) on Chinese consumers' green purchase intention", Asia Pacific Journal of Marketing and Logistics. https://doi.org/10.1108/APJML-05-2019-0285

Liu, M. T., Liu, Y., Mo, Z., Zhao, Z., and Zhu, Z. (2020), 'How CSR influences customer behavioural loyalty in the Chinese hotel industry", Asia Pacific Journal of Marketing and Logistics, Vol. 32 No. 1, pp. 1-22.

Liu, Y., and Liu, M. T. (2019), "Celebrity poses and consumer attitudes in endorsement advertisements", Asia Pacific Journal of Marketing and Logistics, Vol. 31 No. 4, pp. 10271041.

Liu, Y., and Liu, M. T. (2020), "Big star undercover: The reinforcing effect of disfluent celebrity endorsers' faces on consumer's brand memory", Journal of Advertising, Vol. 49 No. 2, pp. 185-194.

Lundblad, L., and Davies, I. A. (2016), "The values and motivations behind sustainable fashion consumption”, Journal of Consumer Behaviour, Vol. 15 No. 2, pp. 149-162.

Madden, T. J., Ellen, P. S., and Ajzen, I. (1992), "A comparison of the theory of planned behavior and the theory of reasoned action", Personality and Social Psychology Bulletin, Vol. 18 No. 2, pp. 3-9.

McCormac, A., Zwaans, T., Parsons, K., Calic, D., Butavicius, M., and Pattinson, M. (2017), "Individual differences and information security awareness", Computers in Human Behavior, Vol. 69, pp. 151-156.

Merkin, R. S. (2006), "Uncertainty avoidance and facework: A test of the Hofstede model", International Journal of Intercultural Relations, Vol. 30 No. 2, pp. 213-228.

Mo. Z., Liu M., and Liu, Y. (2018), "Effects of functional green advertising on self and others", Psychology \& Marketing, Vol. 35 No. 5, pp. 368-382. 
Morgan, L. R., and Birtwistle, G. (2009), “An investigation of young fashion consumers' disposal habits", International Journal of Consumer Studies, Vol. 33 No. 2, pp. 190-198.

Morgan, R. M., and Hunt, S. D. (1994), "The commitment-trust theory of relationship marketing”, Journal of Marketing, Vol. 58 No. 3, pp. 20-38.

Mun, J. M., Ju, H. W., and Johnson, K. K. (2014), "Young consumers and retail borrowing: application of the theory of planned behavior", Journal of Global Fashion Marketing, Vol. 5 No. 1, pp. 60-73.

Nïnimäki, K., and Hassi, L. (2011), "Emerging design strategies in sustainable production and consumption of textiles and clothing", Journal of Cleaner Production, Vol. 19 No. 16, pp. 1876-1883.

Nuttavuthisit, K., and Thøgersen, J. (2017), "The importance of consumer trust for the emergence of a market for green products: The case of organic food", Journal of Business Ethics, Vol. 140 No. 2, pp. 323-337.

Paul, J., Modi, A., and Patel, J. (2016), "Predicting green product consumption using theory of planned behavior and reasoned action", Journal of Retailing and Consumer Services, Vol. 29, pp. 123-134.

Perry, P., and Towers, N. (2009), 'Determining the antecedents for a strategy of corporate social responsibility by small-and medium-sized enterprises in the UK fashion apparel industry”, Journal of Retailing and Consumer Services, Vol. 16 No. 5, pp. 377-385.

Podsakoff, P. M., MacKenzie, S. B., Lee, J. Y., and Podsakoff, N. P. (2003), "Common method biases in behavioral research: a critical review of the literature and recommended remedies", Journal of Applied Psychology, Vol. 88 No. 5, p. 879.

Riemenschneider, C. K., Harrison, D. A., and Mykytyn Jr, P. P. (2003), 'Understanding IT adoption decisions in small business: integrating current theories", Information \& Management, Vol. 
40 No. 4, pp. 269-285.

Sen, S., Bhattacharya, C. B., and Korschun, D. (2006), "The role of corporate social responsibility in strengthening multiple stakeholder relationships: A field experiment", Journal of the Academy of Marketing Science, Vol. 34 No. 2, pp. 158-166.

Sivadas, E., Bruvold, N. T., and Nelson, M. R. (2008), "A reduced version of the horizontal and vertical individualism and collectivism scale: A four-country assessment", Journal of Business Research, Vol. 61 No. 3, pp. 201-210.

Söderlund, M. (2002), "Customer familiarity and its effects on satisfaction and behavioral intentions”, Psychology and Marketing, Vol. 19 No. 10, pp. 861-879.

Straughan, R. D., and Roberts, J. A. (1999), "Environmental segmentation alternatives: a look at green consumer behavior in the new millennium", Journal of Consumer Marketing, Vol. 16 No. 6, pp. 558-575.

Tseng, T. H., Balabanis, G., and Liu, M.T. (2018), "Explaining inconsistencies in implicit and explic it attitudes towards domestic and foreign products", International Marketing Review, Vol. 35 No. 1, pp. 72-92.

Venkatesh, V., Morris, M. G., Davis, G. B., and Davis, F. D. (2003), 'User acceptance of information technology: Toward a unified view", MIS Quarterly, Vol. 27 No. 3, pp. 425-478.

Wang, P., Liu, Q., and Qi, Y. (2014), 'Factors influencing sustainable consumption behaviors: a survey of the rural residents in China”, Journal of Cleaner Production, Vol. 63, pp. 152-165.

Wang, S., Fan, J., Zhao, D., Yang, S., and Fu, Y. (2016), 'Predicting consumers' intention to adopt hybrid electric vehicles: using an extended version of the theory of planned behavior model", Transportation, Vol. 43 No. 1, pp. 123-143.

World Trade Organization (2019), World Trade Statistical Review 2019. Retrieved January 13, 2020 from https://www.wto.org/english/res_e/statis_e/wts2019_e/wts2019_e.pdf 
Yadav, R., and Pathak, G. S. (2016), 'Young consumers' intention towards buying green products in a developing nation: Extending the theory of planned behavior", Journal of Cleaner Production, Vol. 135, pp. 732-739.

Yadav, R., and Pathak, G. S. (2017), 'Determinants of consumers' green purchase behavior in a developing nation: Applying and extending the theory of planned behavior", Ecological Economics, Vol. 134, pp. 114-122.

Yi, Q., and Hohashi, N. (2018), "Comparison of perceptions of domestic elder abuse among healthcare workers based on the Knowledge-Attitude-Behavior (KAB) model', PloS One, Vol. 13 No. 11, pp. 1-14.

Zhou, X., Shi, G., Liu, M., and Bu, H. (2015), "The mediating roles of renqing and ganqing in Chinese relationship marketing", Nankai Business Review International, Vol. 6 No. 2, pp. 156-176. 
Table 1. Summary of recent studies using TPB in context of ethical consumption

\begin{tabular}{|c|c|c|c|}
\hline Literature & Context & $\begin{array}{l}\text { Additional } \\
\text { constructs }\end{array}$ & Findings \\
\hline $\begin{array}{l}\text { Yadav and } \\
\text { Pathak (2016) }\end{array}$ & Green products & $\begin{array}{l}\text { Environmental } \\
\text { concern; } \\
\text { environmental } \\
\text { knowledge }\end{array}$ & $\begin{array}{l}\text { The extended model incorporated with } \\
\text { additional constructs }\left(\mathrm{R}^{2}=0.37\right) \text { have improved } \\
\text { the predictive utility of the original TPB model } \\
\left(\mathrm{R}^{2}=0.27\right) \text {. }\end{array}$ \\
\hline $\begin{array}{l}\text { Yadav and } \\
\text { Pathak (2017) }\end{array}$ & Green products & $\begin{array}{l}\text { Perceived value; } \\
\text { willingness to pay } \\
\text { premium }\end{array}$ & $\begin{array}{l}\text { The extended model showed a better } \\
\text { explanatory power in predicting consumer } \\
\text { green purchase intention }\left(\mathrm{R}^{2}=0.62 \mathrm{vs} . \mathrm{R}^{2}=\right. \\
0.54) \text { and green purchase behavior }\left(\mathrm{R}^{2}=0.32\right. \\
\left.\text { vs. } \mathrm{R}^{2}=0.28\right) \text { in comparison to original TPB } \\
\text { model. }\end{array}$ \\
\hline $\begin{array}{l}\text { Paul, Modi and } \\
\text { Patel(2016) }\end{array}$ & Green products & $\begin{array}{l}\text { Environmental } \\
\text { concern }\end{array}$ & $\begin{array}{l}\text { Extended TPB }\left(\mathrm{R}^{2}=0.55\right) \text { has higher predict } \\
\text { ability than TPB }\left(\mathrm{R}^{2}=0.49\right) \text { and TRA }\left(\mathrm{R}^{2}=0.46\right) \\
\text { in green marketing settings. }\end{array}$ \\
\hline $\begin{array}{l}\text { Liu, Liu and } \\
\text { Mo }(2020)\end{array}$ & Green products & Moral norm & $\begin{array}{l}\text { The extended model exhibited had better } \\
\text { explanatory power }\left(\mathrm{R}^{2}=0.50\right) \text { than the original } \\
\text { TPB model }\left(\mathrm{R}^{2}=0.38\right)\end{array}$ \\
\hline $\begin{array}{l}\text { Jang, Chung } \\
\text { and Kim } \\
\text { (2015) }\end{array}$ & $\begin{array}{l}\text { Environmental } \\
\text { restaurants }\end{array}$ & $\begin{array}{l}\text { Environmental } \\
\text { concern; perceived } \\
\text { effectiveness }\end{array}$ & $\begin{array}{l}\text { The extended TPB model improved } \mathrm{R}^{2} \text { from } \\
0.52 \text { to } 0.55 \text {. }\end{array}$ \\
\hline $\begin{array}{l}\text { Wang et al. } \\
(2016)\end{array}$ & $\begin{array}{l}\text { Hybrid electric } \\
\text { vehicles }\end{array}$ & $\begin{array}{l}\text { Environmental } \\
\text { concern; moral } \\
\text { norm }\end{array}$ & $\begin{array}{l}\text { The inclusion of personal moral norm as an } \\
\text { indicator increased the explained variance by } \\
\text { only } 0.7 \% \text {, from } 33.6 \% \text { to } 34.3 \% \text {. }\end{array}$ \\
\hline $\begin{array}{l}\text { Nuttavuthisit } \\
\text { and Thøgersen } \\
(2017)\end{array}$ & Organic food & Consumer Trust & $\begin{array}{l}\text { The inclusion of trust in TPB model increased } \\
\text { the } \mathrm{R}^{2} \text { from } 0.43 \text { to } 0.49 \text {. }\end{array}$ \\
\hline
\end{tabular}


Table 2. Sample characteristics $(\mathrm{N}=245)$

\begin{tabular}{lll}
\hline Characteristics & Frequency & Percentage \\
\hline Gender & 75 & \\
Female & 170 & 30.61 \\
Male & & 69.39 \\
Age (in years) & 47 & \\
$18-22$ & 48 & 19.18 \\
23 - 30 & 67 & 19.59 \\
31 - 40 & 44 & 27.35 \\
41 - 50 & 39 & 17.96 \\
51 or above & & 15.92 \\
Relationship with the fashion industry & 196 & \\
Consumer & 18 & 80.00 \\
Employee (factory) & 13 & 7.35 \\
Employee (retailer) & 18 & 5.31 \\
Others & & 7.35 \\
Frequently of buying fashion products & 8 & \\
Never of hardly never & 126 & 3.27 \\
Occasionally & 100 & 51.43 \\
Several times a month & 11 & 40.81 \\
Weekly & & 4.49 \\
Spending of last fashion-shopping trip & 16 & \\
Less than 15€ & 61 & 6.53 \\
15€ - 30€ & 83 & 34.90 \\
$31 €$ - 60€ & 85 & 34.69 \\
More than 60€ & & \\
\hline
\end{tabular}


Table 3. EFA and CFA results

\begin{tabular}{|c|c|c|c|c|}
\hline Factors & Items & Meas urement Items & $\begin{array}{l}\text { EFA } \\
\text { Factor } \\
\text { loadings }\end{array}$ & $\begin{array}{l}\text { CFA } \\
\text { Factor } \\
\text { loadings }\end{array}$ \\
\hline \multirow{3}{*}{$\begin{array}{l}\text { Knowledge } \\
\text { about Ethical } \\
\text { Fashion } \\
(\alpha=.89, \\
\mathrm{AVE}=.73)\end{array}$} & Know1 & I believe that I am informed about ethical fashion. & 0.81 & 0.86 \\
\hline & Know2 & I have a precise view of ethical fashion. & 0.83 & 0.82 \\
\hline & Know3 & Ethical fashion is very familiar to me. & 0.82 & 0.88 \\
\hline \multirow{4}{*}{$\begin{array}{l}\text { Trust in the } \\
\text { Fashion } \\
\text { Industry } \\
(\alpha=.85, \\
\mathrm{AVE}=.58)\end{array}$} & Trust1 & The fashion industry has high integrity. & 0.76 & 0.78 \\
\hline & Trust2 & The fashion industry is a socially responsible industry. & 0.69 & 0.75 \\
\hline & Trust3 & $\begin{array}{l}\text { The fashion industry is concerned to improve the well-being } \\
\text { of society. }\end{array}$ & 0.80 & 0.77 \\
\hline & Trust4 & The fashion industry follows high-ethical standards. & 0.85 & 0.75 \\
\hline \multirow{5}{*}{$\begin{array}{l}\text { Attitude towards } \\
\text { Ethical Fashion } \\
(\alpha=.88, \\
\mathrm{AVE}=.60)\end{array}$} & Attitude1 & I consider that buying ethical fashion goods is positive. & 0.57 & 0.63 \\
\hline & Attitude2 & I consider that buying ethical fashion goods is beneficial. & 0.82 & 0.82 \\
\hline & Attitude3 & I consider that buying ethical fashion goods is us eful. & 0.84 & 0.77 \\
\hline & Attitude4 & I consider that buying ethical fashion goods is worthwhile. & 0.82 & 0.82 \\
\hline & Attitude 5 & I consider that buying ethical fashion goods is wise. & 0.84 & 0.80 \\
\hline \multirow{3}{*}{$\begin{array}{l}\text { Subjective Norm } \\
(\alpha=.78, \\
\mathrm{AVE}=.54)\end{array}$} & SN1 & $\begin{array}{l}\text { I believe close friends and family would think it is a good } \\
\text { idea for me to buy ethical fashion goods. }\end{array}$ & 0.67 & 0.81 \\
\hline & SN2 & $\begin{array}{l}\text { I feel important people in my life want me to buy ethical } \\
\text { fashion goods. }\end{array}$ & 0.76 & 0.72 \\
\hline & SN3 & $\begin{array}{l}\text { The people who I listen to could influence me to buy ethical } \\
\text { fashion goods. }\end{array}$ & 0.70 & 0.70 \\
\hline \multirow{3}{*}{$\begin{array}{l}\text { Perceived } \\
\text { Behavioral } \\
\text { Control } \\
(\alpha=.77 \\
\mathrm{AVE}=.54)\end{array}$} & $\mathrm{PBC1}$ & $\begin{array}{l}\text { I have the resources, knowledge and capacity to buy ethical } \\
\text { fashion goods. }\end{array}$ & 0.73 & 0.84 \\
\hline & PBC2 & Buying ethical fashion goods is easy for me. & 0.68 & 0.79 \\
\hline & PBC3 & I have complete control over buying ethical fashion goods. & 0.81 & 0.55 \\
\hline \multirow{2}{*}{$\begin{array}{l}\text { Intention to } \\
\text { purchase } \\
\text { Ethical Fashion } \\
(\alpha=.71, \\
\mathrm{AVE}=.58)\end{array}$} & Intent 1 & I intent to buy ethical fashion goods in the future. & 0.84 & 0.86 \\
\hline & Intent 2 & I will try to buy ethical fashion goods in the future. & 0.66 & 0.64 \\
\hline
\end{tabular}


Table 4. Discriminant validity of measurement model

\begin{tabular}{|c|c|c|c|c|c|c|c|c|c|}
\hline & & Mean & SD & 1 & 2 & 3 & 4 & 5 & 6 \\
\hline 1. & Knowledge about Ethical Fashion & 4.38 & 1.37 & 0.85 & & & & & \\
\hline 2. & Trust in the Fashion Industry & 4.72 & 1.15 & $0.57^{* * *}$ & 0.76 & & & & \\
\hline 3. & Attitude towards Ethical Fashion & 5.59 & 1.08 & $0.33^{* * *}$ & $0.35^{* * *}$ & 0.77 & & & \\
\hline 4. & Subjective Norm & 5.00 & 1.12 & $0.65^{* * *}$ & $0.52^{* * *}$ & $0.52^{* * *}$ & 0.74 & & \\
\hline 5. & Perceived Behaviour Control & 4.79 & 1.19 & $0.66^{* * *}$ & $0.52^{* * *}$ & $0.32^{* * *}$ & $0.70^{* * *}$ & 0.74 & \\
\hline 6. & Intention to purchase Ethical Fashion & 5.82 & 0.91 & $0.49^{* * *}$ & $0.56^{* * *}$ & $0.53^{* * *}$ & $0.73^{* * *}$ & $0.52^{* * *}$ & 0.76 \\
\hline
\end{tabular}

The bold diagonal elements are the square root of the average variance extracted (AVE).

Note: $* * * p<.001$. Correlation is significant at the .001 level (2-tailed). 
Table 5. Common method bias analysis

\begin{tabular}{|c|c|c|c|c|c|}
\hline Factors & Items & $\begin{array}{l}\text { Substantive Factor } \\
\text { Loading (R1) }\end{array}$ & $\mathrm{R} 1^{2}$ & $\begin{array}{l}\text { Method Factor } \\
\text { Loading (R2) }\end{array}$ & $\mathrm{R} 2^{2}$ \\
\hline \multirow{3}{*}{$\begin{array}{l}\text { Knowledge about } \\
\text { Ethical Fashion } \\
(\text { VIF }=1.40)\end{array}$} & Know1 & $0.85^{* *}$ & 0.72 & 0.07 & 0.01 \\
\hline & Know2 & $0.95^{* *}$ & 0.90 & -0.07 & 0.01 \\
\hline & Know3 & $0.92^{* *}$ & 0.84 & 0.00 & 0.00 \\
\hline \multirow{4}{*}{$\begin{array}{l}\text { Trust in the Fashion } \\
\text { Industry } \\
(V I F=1.40)\end{array}$} & Trust1 & $0.82^{* *}$ & 0.67 & 0.02 & 0.00 \\
\hline & Trust2 & $0.69^{* *}$ & 0.47 & $0.17^{* *}$ & 0.03 \\
\hline & Trust3 & $0.86^{* *}$ & 0.75 & -0.04 & 0.00 \\
\hline & Trust4 & $0.95^{* *}$ & 0.90 & $-0.16^{* *}$ & 0.03 \\
\hline \multirow{5}{*}{$\begin{array}{l}\text { Attitude towards } \\
\text { Ethical Fashion } \\
(V I F=1.24)\end{array}$} & Attitude1 & $0.60^{* *}$ & 0.36 & 0.17 & 0.03 \\
\hline & Attitude2 & $0.91^{* *}$ & 0.83 & -0.08 & 0.01 \\
\hline & Attitude 3 & $0.90^{* *}$ & 0.81 & $-0.11^{*}$ & 0.01 \\
\hline & Attitude4 & $0.83^{* *}$ & 0.68 & 0.04 & 0.00 \\
\hline & Attitude5 & $0.85^{* *}$ & 0.71 & 0.00 & 0.00 \\
\hline \multirow{3}{*}{$\begin{array}{l}\text { Subjective Norm } \\
(\text { VIF }=1.64)\end{array}$} & SN1 & $0.81^{* *}$ & 0.65 & 0.06 & 0.00 \\
\hline & SN2 & $0.85^{* *}$ & 0.72 & -0.02 & 0.00 \\
\hline & $\mathrm{SN} 3$ & $0.85^{* *}$ & 0.73 & -0.05 & 0.00 \\
\hline \multirow{3}{*}{$\begin{array}{l}\text { Perceived Behavioral } \\
\text { Control } \\
(\text { VIF }=1.63)\end{array}$} & PBC1 & $0.84^{* *}$ & 0.70 & 0.06 & 0.00 \\
\hline & PBC2 & $0.83^{* *}$ & 0.70 & 0.03 & 0.00 \\
\hline & PBC3 & $0.82^{* *}$ & 0.67 & -0.12 & 0.01 \\
\hline \multirow{2}{*}{$\begin{array}{l}\text { Intention to purchase } \\
\text { Ethical Fashion } \\
(V I F=1.16)\end{array}$} & Intent 1 & $0.79^{* *}$ & 0.62 & $0.14^{* *}$ & 0.02 \\
\hline & Intent2 & $0.98^{* *}$ & 0.96 & $-0.15^{* *}$ & 0.02 \\
\hline Average & & 0.84 & 0.72 & 0.00 & 0.01 \\
\hline
\end{tabular}

${ }^{*} p<.05 ;{ }^{* *} p<.01$, VIFs were obtained by conducting the full collinearity assessment 
Table 6. SEM results of extended TPB model

\begin{tabular}{lllllll}
\hline Hypothesis & Paths & $\begin{array}{l}\text { Standardized } \\
\text { coefficients }^{\text {a }}\end{array}$ & $\begin{array}{l}\text { Direct effect } \\
(95 \% \mathrm{CI})\end{array}$ & $\begin{array}{l}\text { Indirect effect } \\
(95 \% \mathrm{CI})\end{array}$ & $\begin{array}{l}\text { Total effect } \\
(95 \% \mathrm{CI})\end{array}$ & $\begin{array}{l}\text { Hypothesis } \\
\text { Supported }\end{array}$ \\
\hline $\mathrm{H} 1 \mathrm{a}$ & Attitude $\rightarrow$ PI & $0.24^{* *}\left(0.32^{* *}\right)$ & {$[0.09-0.44]$} & - & {$[0.09-0.44]$} & Yes \\
$\mathrm{H} 1 \mathrm{~b}$ & $\mathrm{SN} \rightarrow$ PI & $0.49^{* *}\left(0.62^{* *}\right)$ & {$[0.30-0.67]$} & - & {$[0.30-0.67]$} & Yes \\
$\mathrm{H} 1 \mathrm{c}$ & $\mathrm{PBC} \rightarrow$ PI & $0.02(0.04)$ & {$[-0.12-0.20]$} & - & {$[-0.12-0.20]$} & No \\
$\mathrm{H} 2 \mathrm{a}$ & Trust $\rightarrow$ Attitude & $0.21^{*}$ & {$[0.05-0.37]$} & - & {$[0.05-0.37]$} & Yes \\
$\mathrm{H} 2 \mathrm{~b}$ & Trust $\rightarrow$ PI & $0.24^{* *}$ & {$[0.11-0.36]$} & {$[0.01-0.13]$} & {$[0.16-0.43]$} & Yes \\
$\mathrm{H3a}$ & Knowledge $\rightarrow$ Trust & $0.60^{* *}$ & {$[0.49-0.70]$} & - & {$[0.49-0.70]$} & Yes \\
$\mathrm{H} 3 \mathrm{~b}$ & Knowledge $\rightarrow$ Attitude & $0.25^{*}$ & {$[0.06-0.39]$} & {$[0.04-0.24]$} & {$[0.25-0.50]$} & Yes \\
$\mathrm{H} 3 \mathrm{c}$ & Knowledge $\rightarrow$ SN & $0.70^{* *}$ & {$[0.60-0.78]$} & - & {$[0.60-0.78]$} & Yes \\
$\mathrm{H} 3 \mathrm{~d}$ & Knowledge $\rightarrow$ PBC & $0.70^{* *}$ & {$[0.57-0.79]$} & - & {$[0.57-0.79]$} & Yes \\
- & Knowledge $\rightarrow$ PI & - & - & {$[0.48-0.66]$} & {$[0.48-0.66]$} & - \\
\hline
\end{tabular}

${ }^{*} p<.05 ;{ }^{* *} p<.01 ; \mathrm{SN}=$ Subjective Norm, $\mathrm{PBC}=$ Perceived Behavior Control, $\mathrm{PI}=$ Purchase Intention

${ }^{a}$ The numbers in brackets represents the standardized path coefficients of the original TPB model 
Figure 1. The proposed research frame work

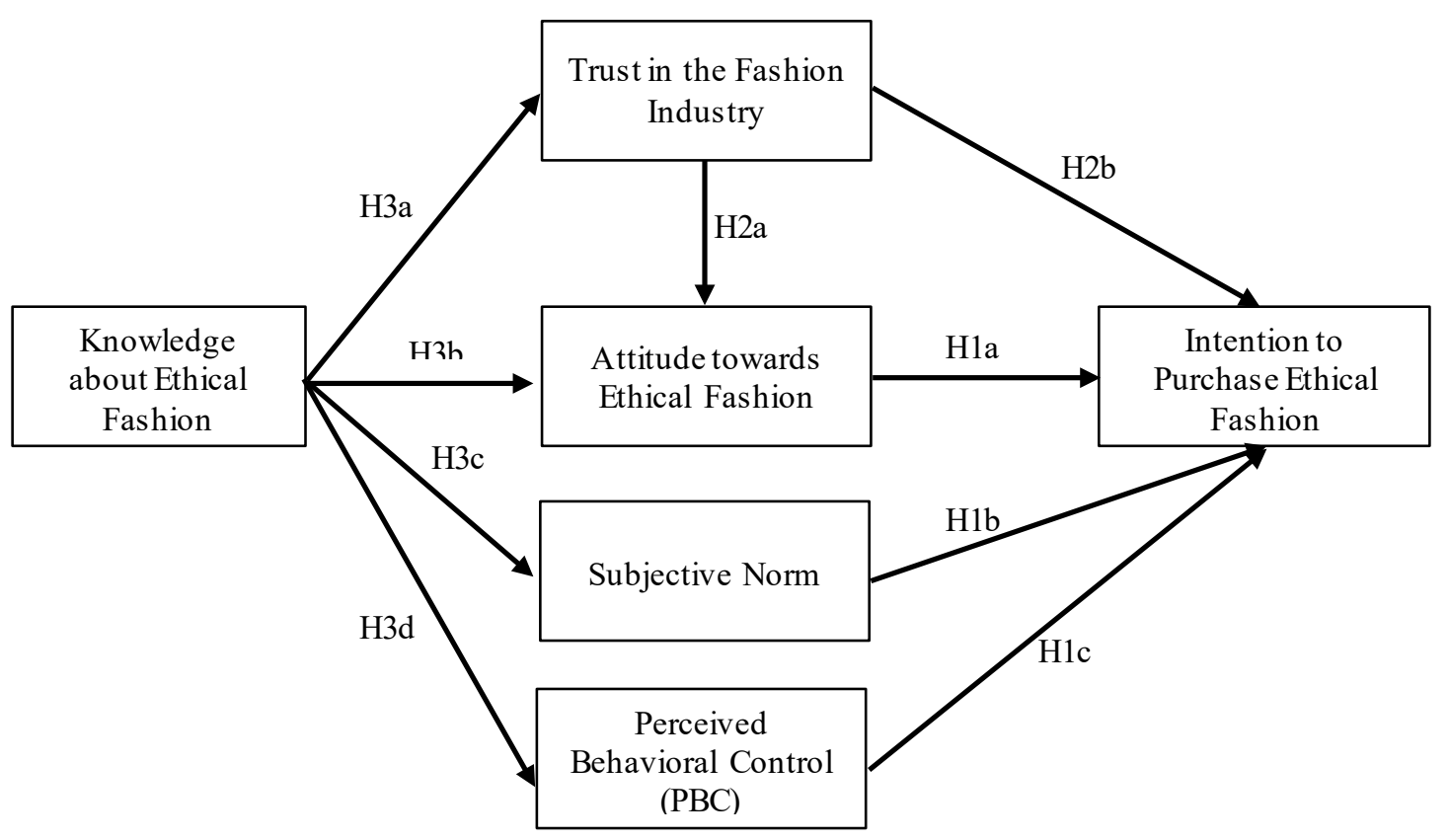




\section{Appendix}

Before you respond to the questionnaire, please read this information and look at the images carefully:

(1) Fashion apparel manufacturers start selling organic collection and fair trade products. H\&M has been selling its "Conscious Collection" since 2011, while Inditex joined the ethical fashion movement in 2015 with the launch of the "Join Life" Collection.

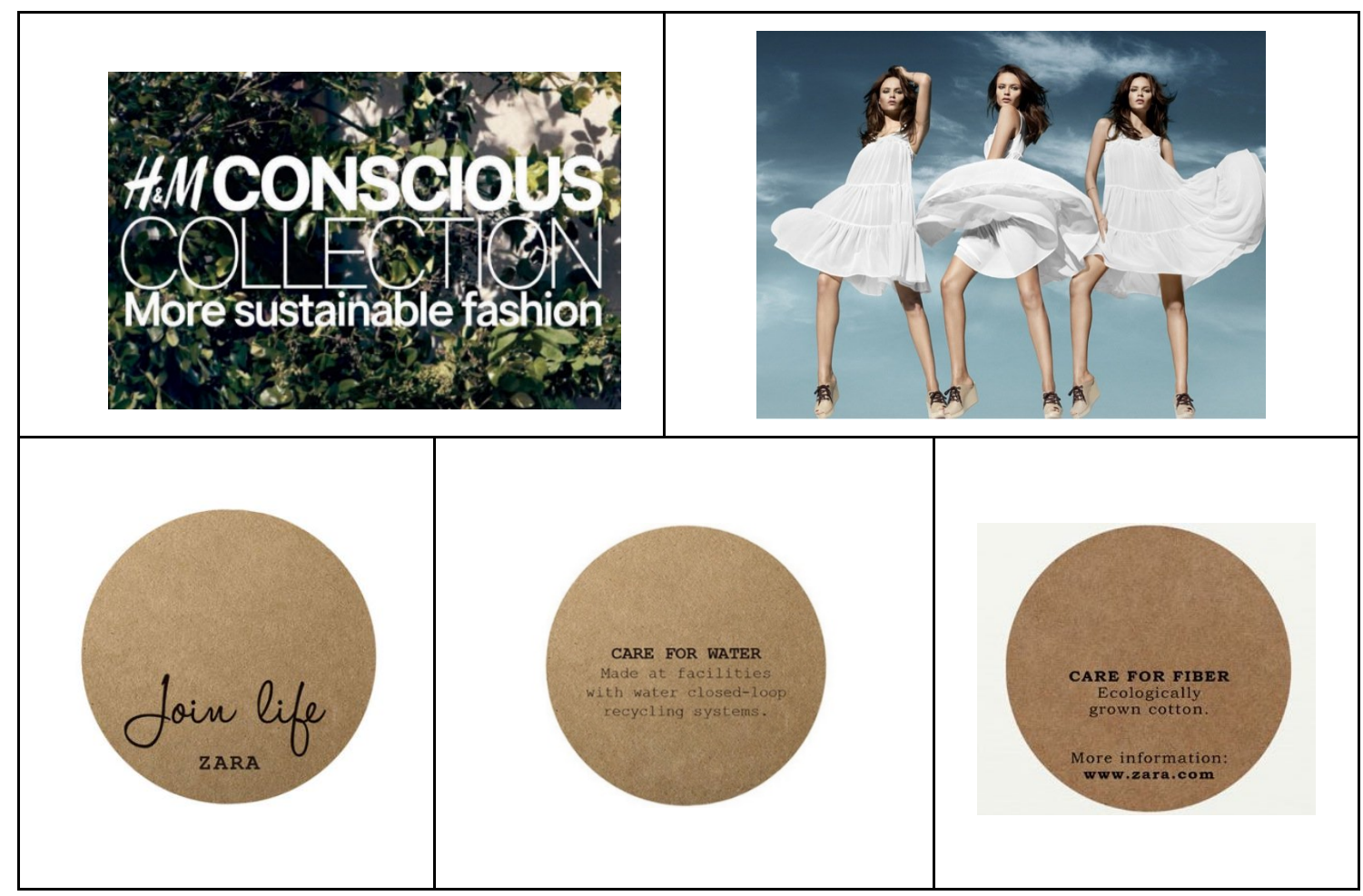

(2) Fashion apparel manufacturers start promoting sustainable supply chain manage ment strategies to reduce the consumption of natural resources in the world. Manufacturers also launch recycling campaigns (e.g., Intimissimi rebuys used products from their customers to reuse them and create new ones). In doing so, customers receive discount coupons for future purchases.

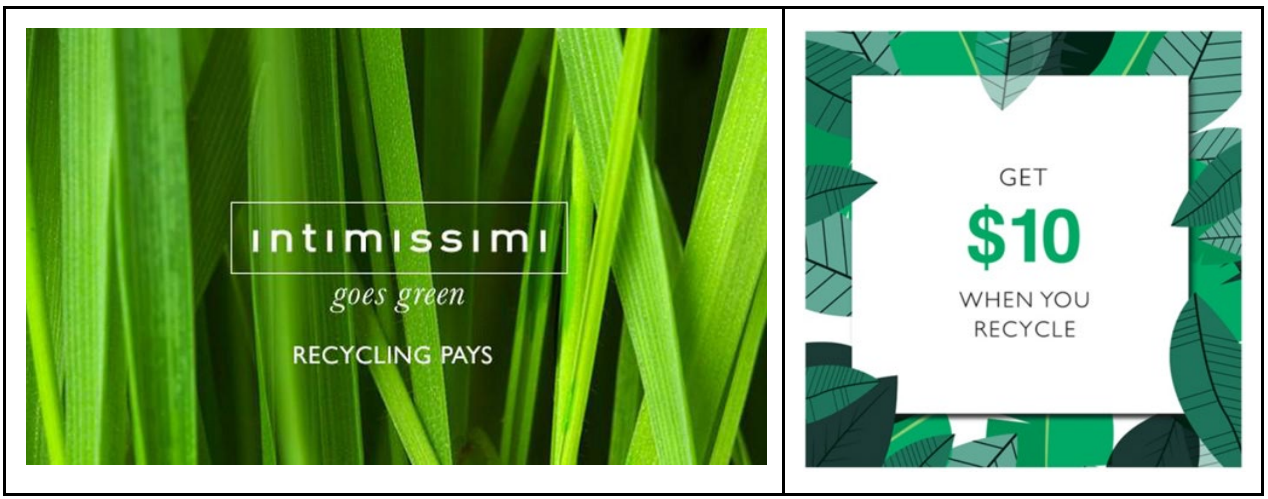

